\title{
A EDUCAÇÃO EM TEMPO INTEGRAL NO CURRÍCULO DO ENSINO MÉDIO INTEGRADO DO IFMG
}

\author{
FULL-TIME EDUCATION IN THE CURRICULUM OF IFMG'S INTEGRATED HIGH SCHOOL
}

Resumo: O presente estudo transita na fronteira entre as políticas curriculares e o currículo do Instituto Federal de Educação, Ciência e Tecnologia de Minas Gerais (IFMG), problematizando as conexões entre a educação profissional de nível médio e a educação em tempo integral (ETI). A seleção e a organização dos saberes curriculares devem realizar-se a partir do direito dos estudantes à formação plena. Contudo, imagens reducionistas e mercantilizadas do currículo pairam sobre a educação profissional tecnológica e ameaçam esse direito. Em tal contexto, analisou-se o currículo do ensino médio integrado do IFMG e suas conexões com a ETI, a fim de contribuir para a construção de propostas que considerem as especificidades das juventudes, dialoguem com os diversos tempos da vida e que problematizem as finalidades da jornada escolar ampliada. A metodologia da pesquisa incluiu a análise dos dados descritivos sobre o texto curricular expressos nas normativas institucionais e nos Projetos Pedagógicos de Cursos (PPCs) de 4 campi do IFMG. Os resultados apontam que os Institutos Federais apresentam em suas normativas interessantes contribuições para a ETI, contudo, os códigos presentes nos seus PPCs contêm as marcas do produtivismo e denotam truncamentos que invisibilizam as múltiplas dimensões da formação humana e as concepções pedagógicas que fundamentam tais projetos.

Palavras-chave: Currículo. Ensino Médio. Educação Profissional. Educação em Tempo Integral.

\begin{abstract}
This study transits among the frontiers between curricular politics and the curriculum of the Instituto Federal de Educação, Ciência e Tecnologia de Minas Gerais (IFMG - Minas Gerais' Federal Institute for Education, Science and Technology), questioning the connections between mid-level professional education and full-time education. The selection and organization of curricular knowledge must be based on the students' right to thorough education. However, reductionist and commodified images of the curriculum hang over professional technological education, threatening this same right. With this context in mind, this study analysed IFMG's integrated high school curriculum and its connections to full-time education, in order to contribute to the development of proposals for curriculums that consider the youths' specificities and establish a dialogue with several moments of life, and that question the purposes of extended school time. The methodology of this research included the analysis of the descriptive data regarding the curricular text conveyed by the institutional regulations and by the Pedagogical Course Projects (PCP) of 4 of the IFMG's campuses. The results suggest that the Federal Institutes show in their regulations some interesting contributions for full-time education; however, the codes found in their PCPs contain signs of productivism, and denote shortnesses that invisibilize the multiple dimensions of the human formation and pedagogical conceptions that are the foundation to such projects.
\end{abstract}

Keywords: Curriculum. High School. Professional Education. Full-time Education.

\footnotetext{
${ }_{1}^{1}$ Professora do Ensino Básico, Técnico e Tecnológico do Instituto Federal Minas Gerais. Doutora em Educação pela Universidade de São Paulo (2019) e membro do Grupo de pesquisas em Educação Física escolar da Faculdade de Educação da Universidade de São Paulo. E-mail: katia.sa.bh@gmail.com. Orcid: https://orcid.org/0000-0002-87265145.

2 Professor Titular da Faculdade de Educação da Universidade de São Paulo, atua nos cursos de graduação e pósgraduação e coordena o Grupo de Pesquisas em Educação Física escolar. E-mail: mgneira@usp.br. Orcid: https://orcid.org/0000-0003-1054-8224.
} 


\section{INTRODUÇÃO}

O presente estudo transita na fronteira entre as políticas curriculares e o currículo do Instituto Federal de Educação, Ciência e Tecnologia de Minas Gerais (IFMG). Parte de um olhar panorâmico sobre o Ensino Médio (EM) e chega aos arranjos específicos do IFMG, do Ensino Médio Integrado (EMI) e da educação em tempo integral (ETI). Nos últimos anos houve acelerada expansão na oferta de ETI no Brasil e o número de matrículas deveria continuar crescendo rumo à meta estabelecida no Plano Nacional de Educação (PNE), que prevê a oferta dessa jornada estendida para, no mínimo, $25 \%$ dos alunos da educação básica da rede pública até o ano de 2024. Entretanto, os desafios para o atingimento da meta proposta ainda são expressivos, principalmente no Ensino Médio (EM). Para Cavaliere (2014), não há conceito ou prática firmados sobre o que seja educação integral escolar, portanto, é necessário formular/aperfeiçoar modelos de trabalho que articulem áreas disciplinares e temáticas, sendo inevitáveis discussões mais aprofundadas sobre currículo.

Na ótica de Sacristán (2013), o currículo é reconhecido no seu processo de desenvolvimento, que envolve três planos: o texto curricular com seus objetivos; o desenvolvimento curricular por meio das práticas, e os efeitos provocados nos alunos. Esses três planos não se correspondem com exatidão, as intenções nem sempre correspondem às práticas. $O$ texto curricular tem seu valor à medida que difunde os códigos sobre o que deve ser a cultura nas escolas, tornando-os públicos, contudo toda proposta de texto é traduzida pelos leitores, que podem enriquecê-la ou mesmo subvertê-la, ou seja, o coletivo escolar tem a possibilidade de criar novas possibilidades e até mesmo de insurgir contra as imposições prescritivas.

Se admitirmos que o currículo é o pilar de um projeto que age de forma intencional, formal e direta na formação dos estudantes e que estes participam compulsoriamente desse projeto dos 4 aos 17 anos, nada mais justo que contemplar os interesses dos discentes e de suas famílias na construção do currículo, ou que pelo menos o currículo seja pensado a partir de uma imagem mais realista e menos idealista sobre quem é esse sujeito educando.

Miguel Arroyo (2007) sugere um debate sobre o currículo a partir dos direitos dos educandos; adverte que algumas imagens e concepções de alunos permanecem incrustadas no imaginário social, nas leis, nas reformas e nas diretrizes curriculares, embora outras novas imagens e concepções estejam se afirmando no olhar docente e administrativo, possibilitando novos ordenamentos e prioridades nos conteúdos curriculares.

Imagens reducionistas e mercantilizadas do currículo apontam para a formação de sujeitos empregáveis, em que os educandos são vistos como "recursos humanos a serem carimbados para o mercado segmentado e seletivo" e os conhecimentos escolares são reduzidos à aquisição de habilidades e competências que o pragmatismo do mercado valoriza (ARROYO, 2007, p. 24). Para repensar os currículos é fundamental superar essa visão reducionista de alunos como empregáveis, principalmente nesse momento de recessão econômica, desregulação do trabalho e insegurança nos mercados. "Ter como referente ético o direito dos educandos ao trabalho e o direito aos conhecimentos e saberes do mundo do trabalho irá além do referente mercantil, do aprendizado de competências" (ARROYO, 2007, p. 26). A seleção e a organização dos saberes curriculares devem realizar-se a partir do respeito aos estudantes em sua totalidade humana, como sujeitos iguais de direitos à formação plena. Nesse sentido, a pluralidade das dimensões da formação humana deve ser contemplada, sem ignorar as dimensões ética, estética, corporal, artística, identitária, entre outras.

Arroyo (2007) reconhece a centralidade do tempo no fazer educativo e ressalta a importância de repensar o currículo levando em consideração os tempos de formação da juventude.

O currículo pode ser o território onde se estabeleça um diálogo pedagógico entre os diversos tempos da vida dos educandos e os tempos do conhecimento e da cultura, do ensinar e do aprender, da socialização e da formação de sujeitos com trajetórias humanas e temporais tão diversas (ARROYO, 2007, p. 48).

O objetivo do presente estudo foi analisar o currículo do EMI do IFMG e suas conexões com a ETI, a fim de contribuir para a construção de um currículo que considere as especificidades das juventudes, dialogue com os diversos tempos da vida e que problematize as finalidades da ETI. 


\subsection{A Educação de Tempo Integral}

A ETI é um dos itens das políticas públicas mencionados na Lei de Diretrizes e Bases da Educação Nacional em vigor e no Plano Nacional de Educação (PNE) aprovado em 2014. Dispondo de uma agenda favorável, ela passou a ser oferecida em larga escala no Brasil a partir de 2007, quando o governo federal criou o Programa Mais Educação (PME). As experiências anteriores não tiveram propagação e longevidade, tais como: a Escola Parque concebida por Anysio Teixeira, em Salvador, no ano de 1950 e, em Brasília, em 1960; na mesma época surgiram os Ginásios Vocacionais em São Paulo; posteriormente os Centros Integrados de Educação Pública (Cieps) no Rio de Janeiro, nas décadas de 1980 e 1990; o Programa de Formação Integral da Criança (Profic), entre os anos de 1986 e 1993 em São Paulo, e os Centros Integrados de Atenção à Criança (Ciacs) em 1991.

Houve uma agenda favorável à consolidação da ETI entre 2007 a 2016, resultante do conjunto de ações governamentais, não governamentais e de demandas sociais. Porém é necessário atentar para a concepção de educação integral assumida pelas diferentes iniciativas e acompanhar o desenvolvimento dos programas, a fim de garantir o alcance de suas finalidades e o atendimento das necessidades dos alunos (BARRETO; SÁ, 2016).

O Decreto $n^{\circ}$ 6.253/2007 regulamentou a educação básica em tempo integral como sendo a "jornada escolar com duração igual ou superior a sete horas diárias, durante todo o período letivo, compreendendo o tempo total que um mesmo aluno permanece na escola ou em atividades escolares" (art. $4^{\circ}$ ). Educação Integral não é o mesmo que educação em tempo integral, não há oposição entre esses termos e é até mesmo desejável que a segunda contemple a primeira.

Para Gadotti (2009), as diversas experiências de educação integral têm em comum tanto uma dimensão quantitativa (mais tempo na escola e no seu entorno), quanto uma dimensão qualitativa (a formação integral do ser humano). Essas duas dimensões são inseparáveis. Ele também afirma que o conceito de integralidade deve ser entendido como um princípio organizador do currículo escolar e que numa escola de tempo integral o currículo deve proporcionar a integração de todos os saberes aí desenvolvidos, de forma interdisciplinar, transdisciplinar, intercultural, intertranscultural e transversal, baseando a aprendizagem nas vivências dos alunos.

Maurício (2009, p. 26) apresenta um conceito de educação integral que abarca a amplitude da formação humana por meio das diferentes linguagens:

A concepção de educação integral com a qual partilhamos, que embasa a proposta de extensão do tempo escolar diário, reconhece a pessoa como um todo e não como um ser fragmentado, por exemplo, entre corpo e intelecto. Entende que esta integralidade se constrói através de linguagens diversas, em variadas atividades e circunstâncias.

Galian e Sampaio (2012, p. 407) retomam os questionamentos de Menezes (2009) sobre as intenções por trás da ampliação da jornada escolar e acrescentam que manter as crianças e os jovens longe das ruas enquanto seus pais trabalham seja uma preocupação da educação integral e

Muito provavelmente uma preocupação maior com a garantia das necessidades práticas do mundo do trabalho ou até para assegurar tranquilidade às pessoas nos espaços públicos, do que o cuidado com aquelas questões que respondem a uma formação integral das crianças e jovens nas escolas.

De acordo com Barreto e Sá (2016), as pesquisas sobre a ETI revelam que o contexto da realização está distante do contexto da formulação no que se refere às suas finalidades presentes nos documentos oficiais. Ainda não há uma visão clara sobre o currículo da escola de tempo integral e essa política foi implementada de forma precipitada e com recursos insuficientes. Num ambiente de desconfianças, incertezas, improvisos e falta de condições adequadas, as escolas, pressionadas por interesses eleitorais, foram obrigadas a implantar o tempo integral sem que houvesse diálogo e orientação. Nos contextos pesquisados, as experiências são heterogêneas e os avanços, quase sempre insuficientes para atender à meta prevista no PNE. 
Nota-se que os programas de ETI carregam muitas fragilidades, sendo uma delas a carência de pressupostos sobre as finalidades da educação integral. Embora a espinha dorsal do PME e do Programa Ensino Médio Inovador (ProEMI) ${ }^{3}$ apontem a intencionalidade da busca de uma integração entre os diferentes saberes, nem sempre as redes estaduais e municipais caminham nesse sentido. Alguns programas de ETI explicitam a intenção de ampliar a jornada para oferecer reforço escolar, ou seja, oferecer mais do mesmo. Outros programas são assistencialistas e evidenciam como principal finalidade tirar as crianças e jovens das ruas.

Do ponto de vista econômico ou produtivista, a escolarização pode ser interpretada como a forma de participação das crianças e jovens na divisão social do trabalho, como forma de agregar valor ao capital humano (QVORTRUP, 2014, 2015). Desse modo, ao ampliar a jornada dos alunos sem questionar as finalidades dessa política, a ETI pode se reduzir a uma forma produtivista de controle externo do tempo da criança e do jovem, preparando-os para ocupar funções em jornada de tempo integral, ao mesmo tempo em que possibilita aos pais se dedicarem integralmente ao trabalho.

Em geral, a implantação da jornada escolar ampliada precede a discussão sobre a reordenação do projeto político-pedagógico da escola e sobre o currículo integrado. Como resultado os programas de ETI induzem as escolas a funcionarem com dois currículos distintos e apartados, um para o turno regular e outro para o contraturno.

A dualidade no currículo das escolas de tempo integral de EM são frequentemente associadas à formação geral e formação para o trabalho. O conceito de formação integral nas normativas para a educação profissional e tecnológica (EPT) se concentra na formação do trabalhador e alude à superação da dicotomia entre trabalho manual e intelectual. Os eixos para a construção do currículo integrado são a ciência, a tecnologia, o trabalho e a cultura. A concepção de educação integral nesse caso apresenta-se associada à politecnia, perspectiva diferente da referida nos programas de ETI, contudo a educação profissional pretendida no EMI apresenta o desafio comum de desenvolver um currículo que integre os diferentes saberes.

O número de estudantes do EM matriculados no regime de tempo integral praticamente dobrou nos últimos 5 anos, embora represente apenas 10,8\% das matrículas totais dessa etapa (INEP, 2014, 2019). Contudo a maioria dos estudos sobre ETI concentram-se nas experiências desenvolvidas no Ensino Fundamental, onde o percentual de estudantes matriculados em tempo integral era ${ }^{4}$ bem superior.

De acordo com Silveira (2017), mesmo com o crescimento observado nas matrículas do EM estudos sobre o tempo integral nesse nível de ensino são escassos e ainda há muito a ser pesquisado. Essa autora desenvolveu uma pesquisa sobre as experiências e marcas vividas pelos jovens de um campus do Instituto Federal do Espírito Santo (IFES), na perspectiva da ETI. Sua análise indica que o tempo escolar do IFES desconsidera esferas de sociabilidades juvenis, tais como: a convivência familiar, o lazer, as atividades esportivas e culturais, as amizades e os amores. A autora sugere que as experiências, necessidades e expectativas dos jovens sejam ouvidas e tornadas visíveis ao se planejar e implementar um projeto de ETI e que ele seja pautado na pluralidade juvenil e na concepção de formação humana.

\section{MATERIAL E MÉTODOS}

A partir dos pressupostos teórico-metodológicos que subsidiam a investigação qualitativa, desenvolveu-se a análise do currículo do EMI do IFMG e suas conexões com a jornada escolar em tempo integral, por meio de dados descritivos sobre o texto curricular expressos em diferentes documentos. No presente estudo, o texto curricular foi analisado por meio da interpretação das normativas institucionais e dos Projetos Pedagógicos de Cursos (PPCS). A análise documental foi desenvolvida a partir dos seguintes materiais acessados na Pró-reitora de Ensino (PROEN) do IFMG em outubro de 2017: 1) Plano de Desenvolvimento Institucional (PDI) e Projeto Pedagógico Institucional (PPI), publicados pela Reitoria;

\footnotetext{
${ }^{3}$ O ProEMI, instituído pelo MEC por meio da Portaria n. 971/2009, foi uma das políticas de estímulo à ampliação da jornada escolar, com vistas a apoiar e fortalecer o desenvolvimento de propostas curriculares inovadoras e melhorar a qualidade do ensino (BRASIL, 2009).

4 Em 2019 o percentual de matrículas em tempo integral no Ensino Médio ultrapassou o percentual do Ensino Fundamental. (INEP, 2019)
} 
2) Dez PPCs elaborados pelos campi e enviados para aprovação e registro da PROEN. Trata-se de documentos textuais, no formato eletrônico, classificados como oficiais e públicos, acessados num arquivo aberto (FLICK, 2009). Entre os 18 campi do IFMG, detivemo-nos nos PPCs dos quatro campi da região metropolitana, aqui denominados Campus 1, Campus 2, Campus 3 e Campus 4, pois foram inaugurados na última década, construídos no bojo das políticas para o EMI da rede federal entre 2007 e 2016, e porque apresentam propostas curriculares recentes. Diferentemente de outros campi, criados a partir de instituições federais pré-existentes, os campi da região metropolitana não foram atravessados pelas reformas educacionais do século XX, embora não estejam livres de suas influências.

\section{RESULTADOS E DISCUSSÃO}

Os PPCs analisados foram produzidos entre os anos de 2015 e 2017 e coletados em outubro de 2017 nos arquivos da PROEN. A elaboração obedeceu às normativas do IFMG, publicadas entre 2012 e 2014, representadas pelo Regimento de Ensino, PDI e PPI e pelas "Orientações para elaboração e atualização de projetos pedagógicos dos cursos técnicos do IFMG" (IFMG, 2012).

O documento que disciplina as atividades de ensino comuns aos vários órgãos e setores do IFMG é o Regimento de Ensino. Trata-se de um conjunto de normas cujo objetivo é complementar e normatizar as disposições estatutárias e regimentais gerais. O Regimento de Ensino que orientou a elaboração dos PPCs analisados foi publicado em 2013, tendo sido revogado com a aprovação do Regulamento de Ensino dos Cursos de Educação Profissional Técnica de Nível Médio do IFMG, por meio da Resolução nº 031 de 14/12/2016. De um modo geral, os documentos do IFMG apresentam várias versões. Esse movimento de revisão periódica das normativas estende-se a um conjunto de documentos que orienta a construção curricular, o que indica que os campi estão continuamente revendo suas prescrições a fim de alinhá-las às normativas elaboradas pela Reitoria, e o mesmo ocorre no sentido inverso.

O PDI (IFMG, 2014) é um instrumento gerencial por meio do qual se apresentam os objetivos estratégicos, metas e ações propostas para o período de 2014 a 2018. A maior parte do documento apresenta conteúdo relacionado ao planejamento estratégico, com diagnósticos e planos de expansão. Um dos capítulos é dedicado à apresentação do PPI.

Em linhas gerais, as normativas apresentam características de um instrumento gerencial. Não abordam pressupostos do campo do currículo, nem tampouco explicitam a concepção pedagógica adotada pelo IFMG. O PPI prioriza as finalidades e objetivos definidos em lei para os IFs, com poucos acréscimos referentes ao projeto específico do IFMG. Ele relaciona as políticas de ensino que serão implementadas no período 2014-2018, que contemplam temáticas diversas como evasão; investimento nas instalações e equipamentos; promoção da educação à distância e de metodologias inovadoras, entre outras. Destaca-se uma das políticas referidas nesse documento, que explicita a submissão das práticas pedagógicas aos interesses de poder do mercado de trabalho.

g) formulação e implementação de um sistema de avaliação interna e externa dos projetos pedagógicos implantados e da qualidade final dos cursos, visando a uma contínua avaliação dos componentes curriculares e das práticas pedagógicas, analisando sua real aderência ao mundo moderno e ao mercado de trabalho (IFMG, 2014, p. 44-45).

O PPI foi elaborado a partir das discussões geradas nas comissões centrais e locais criadas para esse fim, mas não há nenhuma referência clara sobre os redatores desse documento. Diante da análise do seu conteúdo, indaga-se qual foi a contribuição do campo pedagógico na elaboração do texto final do PPI, em virtude da invisibilidade dos pressupostos do campo da Educação e da imposição da cultura empresarial num documento pedagógico.

O PPC de cada campus do IFMG foi elaborado de acordo com orientações minuciosas contidas na instrução normativa $\mathrm{n}^{\circ}$ 002/2012 da PROEN e do documento orientador (IFMG, 2012), que indica que a finalidade do PPC é orientar e organizar as práticas pedagógicas do curso, sua estrutura curricular, as ementas, a bibliografia, o perfil profissional dos concluintes e tudo o que se refere ao desenvolvimento do currículo, obedecidas as Diretrizes Curriculares Nacionais para o Ensino Profissional Tecnológico de Nível Médio (DCN-EPT). Embora o documento orientador sugira que os PPCs sejam elaborados numa 
perspectiva emancipatória, ele se fundamenta principalmente nas exigências burocráticas contidas nas DCN-EPT, relegando ao segundo plano as Diretrizes Curriculares Nacionais para o Ensino Médio (DCNEM). O texto elenca rigidamente os tópicos constituintes, enfatizando a formação profissional em vários deles e, por vezes, subordinando essa formação ao mercado de trabalho. Esse documento apresenta algumas incongruências ao recomendar princípios emancipatórios em benefício da sociedade e ao mesmo tempo subordiná-los à formação de um trabalhador que atenda aos interesses do mercado, colocando em segundo plano a formação humana. De acordo com Silva, Silva e Molina Neto (2016, p. 326), proporcionar a formação para o pensar é uma tarefa dos Institutos Federais (IFs) e isso "só poderá acontecer se não se restringir à capacitação técnica exigida pelos interesses de um mercado de trabalho".

Ao subordinar a formação aos interesses do mercado e ressaltar princípios de qualidade e eficiência na formação, as prescrições se aproximam de perspectivas instrumentais, apoiada nos pressupostos da razão instrumental, "que busca sua legitimação pelo atendimento eficiente a determinados fins, sem problematizar os processos que levam a esses fins" (LOPES; MACEDO, 2011, p. 73). Nessa perspectiva o conhecimento a ser selecionado para o currículo deve estar vinculado à formação de habilidades e de conceitos necessários à produtividade social e econômica.

Embora as prescrições do IFMG contenham alguns traços das teorias críticas e abram caminhos para os campi elaborarem coletivamente os PPCs, elas cedem espaço aos interesses de poder do mercado que sobrepujam os interesses dos demais grupos sociais. As prescrições revelam uma prevalência da racionalidade técnica e do discurso eficientista, seja ao enfatizarem questões relacionadas à organização, eficiência e avaliação, seja ao ignorarem os conceitos relacionados à emancipação, relações sociais de produção, identidade e diferença. Contudo nota-se um movimento interessante no sentido de rever continuamente as prescrições, indicando que podem ser transformadas pelas intervenções operadas pelos coletivos dos campi, posto que o ambiente institucional é democrático e dinâmico.

\subsection{Os PPCs produzidos nos campi}

Compuseram o referencial empírico da análise documental os PPCs de dez cursos de EMI dos quatro campi integrantes da pesquisa. Os textos dos PPCs refletem a fragmentação entre formação propedêutica e profissional, com ênfase na formação técnica do profissional, embora essa ênfase não se expresse na matriz curricular, que reserva aproximadamente um terço da carga horária total do curso à formação técnica e profissionalizante. Embora os cursos tenham cargas horárias elevadas e enfatizem a preparação do estudante para a inserção no mundo do trabalho, nenhum deles inclui o estágio na matriz curricular, sendo essa uma atividade não obrigatória. Os alunos podem realizar estágio não-obrigatório como atividade optativa, porém, como cumprem jornada escolar integral, na maior parte das vezes a realização torna-se inviável.

Três dos quatro campi estudados iniciaram suas atividades em sedes provisórias, com longos períodos de funcionamento em instalações inadequadas, à espera da conclusão das obras da sede própria, que se alongaram por seis a sete anos. O Campus 4 iniciou suas atividades em sede própria, porém num prédio que não foi construído para abrigar um IF.

Além da falta de infraestrutura dos campi e do estágio não obrigatório, nota-se nos documentos analisados a ausência de referências que relacionem a formação à dimensão da cultura. A Lei $\mathrm{n}^{\circ}$. 11.892/2008 determina que a oferta formativa dos IFs seja "em benefício da consolidação e fortalecimento dos arranjos produtivos, sociais e culturais locais, identificados com base no mapeamento das potencialidades de desenvolvimento socioeconômico e cultural no âmbito de atuação do Instituto Federal" (inciso IV do artigo $6^{\circ}$. da Lei 11.892/2008). As DCNEM (BRASIL, 2012) reconhecem a centralidade da cultura ao destacar a necessidade de integração entre a educação e as dimensões do trabalho, da ciência, da tecnologia e da cultura como base da proposta e do desenvolvimento curricular. Os PPCs priorizam a dimensão do trabalho e incorporam as dimensões da ciência e tecnologia. Contudo a dimensão da cultura está invisibilizada nos documentos analisados e isso indica uma divergência em relação às diretrizes dos IFs e das DCNEM.

O que se observa é que a perspectiva instrumental ainda paira sobre os currículos dos cursos profissionalizantes que privilegiam o conhecimento técnico em detrimento da formação integral. A crítica neomarxista desvelou as relações entre o conhecimento técnico e a estrutura e funcionamento da 
sociedade capitalista, devido a sua relevância para a economia e a produção. Porém "é esse tipo de conhecimento que acaba sendo visto como tendo prestígio, em detrimento de outras formas de conhecimento, como o conhecimento estético e artístico, por exemplo" (SILVA, 2016, p. 48).

Um estudo desenvolvido pela PROEN revelou que as matrizes curriculares dos cursos de EMI do IFMG atribuem pouco espaço para as disciplinas de Artes, Sociologia e Filosofia, enquanto priorizam as disciplinas de Língua Portuguesa e Matemática (IFMG, 2018). Os PPCs confirmam essa tendência e revelam que a formação do sujeito em todas as suas dimensões é pouco abordada, apesar da formação integral ser um princípio citado em todos os PPCs. Essa configuração reforça uma hierarquização disciplinar, em que

se supervalorizam as chamadas disciplinas científicas, secundarizando-se os saberes referentes às artes e ao corpo. Nessa hierarquia, separam-se a razão da emoção, a teoria da prática, o conhecimento da cultura. Nessa hierarquia, legitimam-se saberes socialmente reconhecidos e estigmatizam-se saberes populares (MOREIRA; CANDAU, 2007, p. 25).

Há uma valorização explícita da dimensão do trabalho na maioria dos PPCs analisados. As referências ao mercado de trabalho são recorrentes, como ilustra esse excerto:

Objetiva-se com isso, não só atender às expectativas do mercado e da sociedade em relação a esses profissionais, mas também desenvolver nestes um senso de protagonismo, necessário para que eles se destaquem ainda mais no mercado de trabalho e busquem por caminhos de sucesso (PCC Automação Industrial, Campus 1, p. 19).

Resultados semelhantes foram apresentados por Bresci (2017), que pesquisou o currículo do campus Inconfidentes, pertencente ao IFSULDEMINAS. A autora aponta que a formação profissional desse campus esteve atrelada ao mercado de trabalho, numa perspectiva utilitarista e muito distante do que se preconiza para uma formação integrada de nível médio. A dualidade permanece mesmo após o delineamento de uma nova proposta formativa no século XXI, na qual persiste a centralidade do trabalho enquanto profissionalização.

Em alguns PPCs a dimensão da cultura e o reconhecimento da importância da rede de significações na construção curricular se faz presente, como nesse excerto do PPC do Campus 3, que afirma que o princípio pedagógico adotado "permite pensar os cursos de forma flexível, com uma ampla rede de significações, e não apenas como um lugar de transmissão do saber" (PPC de Administração, Campus 3, p. 12).

Contudo, a maioria dos PPCs se fundamenta na lógica disciplinar, visivelmente elaborados para atender às normativas, focados na formação técnica, e não enunciam a proposta pedagógica do campus, evidenciando pouca autonomia e protagonismo do coletivo escolar na definição de um norte para a formação oferecida. Embora não esteja explícito, os textos dos PPCs remetem às teorias tradicionais de currículo, que tomam o conhecimento existente como inquestionável. A ausência de referências, na maioria dos PPCs, sobre as disputas em torno do currículo e a luta travada entre os diferentes grupos sociais pela imposição dos sentidos e significados de suas culturas na sociedade é um indicativo do assentimento de uma cultura de caráter universal. A proposta contida em alguns PPCs parte do princípio de que existe um conhecimento universal e natural que deva fazer parte de um currículo que forme para o trabalho, admitindo uma crença na harmonia social e eliminando as contradições sociais (LOPES; MACEDO, 2011), como aludem os excertos abaixo:

Os conteúdos do ensino básico foram definidos com o intuito de prover os discentes dos conhecimentos exigidos pela sociedade brasileira para pessoas egressas de um nível médio de ensino [...] Objetiva-se desenvolver um perfil de aluno capaz de lidar com quaisquer desafios técnicos existentes na indústria, hábil em buscar e assimilar informações e capaz de se adaptar rapidamente às constantes mudanças tecnológicas experimentadas pela área, e assim manter-se atualizado e competitivo no mercado por muitos anos após de sua formatura. Além disso, o curso também proporcionará ao aluno 
conhecimentos e capacidade de dar continuidade a seus estudos em outros níveis de ensino (PPC de Automação Industrial, Campus 1, p. 14).

Para o educando, uma formação de ensino básico e profissional num mesmo espaçotempo, significa sua inserção de forma mais segura no mundo do trabalho e, consequentemente, melhoria na qualidade de vida, bem como sua garantia da continuidade nos estudos em nível superior (PPC de Automação Industrial, Campus 1, p. 15).

Os fragmentos reforçam a visão instrumental do EM que o concebe como uma ponte para algo que está porvir, seja a inserção no mundo do trabalho ou a próxima etapa dos estudos. A formação dos jovens, suas demandas e seu presente são invisibilizados nos projetos. Admitem-se como suficientes as prescrições e regulamentações definidas na esfera federal, visto que muito pouco se acrescenta nos PPCs no que concerne às demandas da comunidade escolar. As particularidades do projeto localizam-se nas ementas e bibliografias dos componentes curriculares, que via de regra são elaboradas individualmente, numa perspectiva disciplinar, a partir da concepção de mundo e de sujeito que cada professor traz consigo e que nem sempre considera as particularidades que se apresentam no contexto escolar.

Os PPCs do Campus 2 trazem algumas particularidades, pois se apresentam como um projeto mais autoral e mais alinhado à proposta dos IFs de minimizar a dualidade entre a formação propedêutica e profissional. Talvez isso se deva ao fato desse campus não ter experimentado a pressa para implementar o EMI imposta aos demais campi e do seu coletivo docente ter desfrutado de mais tempo para elaborar os PPCs ao longo do segundo semestre de 2016. Os PPCs desse campus são menos burocráticos e fornecem mais elementos para os docentes construírem suas propostas curriculares, comparados aos demais. Seus documentos incorporam, ainda que timidamente, as orientações presentes nas DCNEM.

Em consonância aos princípios das DCNEM, reconhece-se que toda formação é a um só tempo geral e profissional. Os cursos técnicos integrados ao Ensino Médio no campus buscarão desenvolver uma formação para cidadania por meio, sobretudo, de projetos interdisciplinares desenvolvidos ao longo do curso (PPC Campus 2, p. 43).

A perspectiva disciplinar talvez seja um dos entraves para a construção do currículo integrado nos IFs. Para Lopes (2008), a organização curricular nas escolas permanece centrada nas disciplinas escolares, mesmo quando propostas de currículo integrado são valorizadas. Embora as diretrizes curriculares orientem a adoção de eixos estruturantes e integradores para o currículo do EM elas não foram capazes de desconstruir a matriz disciplinar. Segundo Lopes e Macedo (2002), a matriz disciplinar é uma tecnologia de organização curricular que desenvolve mecanismos de organização e controle da escola.

Por um simples quadro de horário escolar, são definidos e controlados os conteúdos a serem ensinados, as atividades de professores e de alunos, bem como o espaço e o tempo dessas atividades. A utilização da tecnologia de organização disciplinar, no entanto, não impede, ao longo da história do currículo, a organização de diferentes mecanismos de integração, seja pela criação de disciplinas integradas ou pela tentativa de articulação de disciplinas isoladas (LOPES, 2008, p. 82)

Bezerra (2013) analisou 62 matrizes curriculares e 22 PPCs de EMI dos IFs entre os anos de 2010 e 2012. Constatou que a maioria das matrizes curriculares se limita a justapor em uma grade os componentes curriculares de formação básica e técnica e suas respectivas cargas horárias, acrescentando que

Não foram identificadas nas matrizes curriculares catalogadas, portanto, indícios de uma organização curricular que relacione os conhecimentos de formação geral e formação profissional, o que nos permite afirmar que a histórica dualidade dessas formações está presente nesses documentos institucionais (BEZERRA, 2013, p. 94).

A maioria dos PPCs analisados por Bezerra objetivava somente fins profissionalizantes. Quanto à integração curricular, quase todos "não mencionaram, e muito menos especificaram, se é como suas organizações curriculares miram para a integração entre a formação geral e formação profissional" (BEZERRA, 2013, p. 110).

Entre os PPCs analisados no presente estudo, observa-se a justaposição de matrizes curriculares da formação geral e profissional identificada no estudo de Bezerra, contudo dois campi mencionaram em 
seus PPCs uma organização curricular que mira a integração, sendo que um deles, o Campus 2, detalhou estratégias para esse fim - os "Núcleos Politécnicos" e o "Projeto Integrador". Esse campus, diferentemente dos demais, apresenta nos textos dos PPCs pressupostos para a formação integral e o compromisso com a Educação Básica ao amparar-se nas DCNEM. Ressalta-se que seus PPCs são os mais recentes, tendo sido finalizados em 2017. Esse dado permite supor que os demais campi estejam discutindo seus PPCs e suas práticas no sentido de aprimorar a integração curricular e que suas próximas versões incorporem os avanços resultantes dessas discussões. Embora o Campus 2 seja o único que apresente PPCs com uma estrutura detalhada para o desenvolvimento da integração curricular, há outros campi que revelam intenções nesse sentido, contudo sem detalhar como a integração pode ser desenvolvida.

Bezerra (2013) alerta que não bastam as referências das diretrizes para construir um currículo integrado, seria necessário um esforço maior no sentido de construir uma proposta que supere os equívocos das diretrizes a fim de delinear estratégias de ação para a concretização da integração curricular.

O discurso acadêmico de formação politécnica/omnilateral/humana integral foi, na verdade, hibridizado de tal forma nas novas diretrizes curriculares que se as instituições de ensino seguirem somente suas prescrições continuarão perpetuando a dualidade entre formação propedêutica e formação profissionalizante dado que não saberão como colocar, realmente, em prática a integralização entre EM e EPT (BEZERRA, 2013, p. 114).

Diante do processo acelerado de expansão dos IFs, Moura (2012) alertou que se corria o risco de negligenciar a construção de projetos políticos-pedagógicos bem fundamentados, elaborados coletivamente e coerentes com a realidade regional das novas unidades. Além disso, alertou para o necessário investimento na formação pedagógica dos jovens professores que estavam ingressando nos IFs - mestres e doutores recém-formados -, muitos deles bacharéis com poucos conhecimentos na área da educação e mais especificamente no campo da educação profissional, campo ausente até mesmo nos currículos das licenciaturas. Nesse ponto vale ressaltar que a acelerada expansão foi providencial, principalmente nas regiões periféricas, pois possibilitou a milhares de estudantes a oportunidades de ingressarem em instituições que estão apresentando forte demanda para o EMI. Além disso, as comunidades no entorno dos IFs podem se beneficiar dos seus projetos de pesquisa e extensão e dos cursos de formação inicial e continuada (FIC).

A falta de integração curricular observada nos estudos de Moura (2012) e Bezerra (2013) é um fenômeno que se repete no IFMG, constatado pelas análises dos PPCs. Os documentos revelaram intenções no sentido de construir identidades profissionais que atendam às demandas do mercado, relegando ao segundo plano as demandas dos jovens que estão cursando a última etapa da Educação Básica e que carregam em si múltiplas dimensões formativas que não se encerram na dimensão profissional.

A adoção do Trabalho como um eixo estruturante para o currículo do EM são desafiadoras para os docentes. As relações entre trabalho e educação não são muito discutidas na formação inicial, nem mesmo na formação em serviço dos professores que atuam no IFMG. Moura (2012) alertou sobre a ausência de estudos do campo da educação profissionalizante nos currículos das licenciaturas. A fim de minimizar essa lacuna, os IFs passaram a oferecer o Mestrado Profissional em Educação Profissional e Tecnológica em Rede Nacional (ProfEPT), cujo objetivo é proporcionar formação em educação profissional e tecnológica, com o intuito de contribuir para a melhoria da qualidade do ensino e para o desenvolvimento de pesquisas na área. Metade das vagas do ProfEPT é destinada aos servidores da rede federal, porém ainda não se sabe o impacto dessa ação na atuação docente.

Cabe problematizar a seleção dos conhecimentos associados à dimensão do trabalho que integram o currículo do EMI e como estão sendo abordados. Talvez seja necessário analisar a pertinência das prescrições do Catálogo Nacional de Cursos Técnicos (CNCT) e como são ressignificadas nos PPCs. Mas como essa questão extrapola os objetivos do presente estudo, limitamo-nos a apontar a necessidade de outras investigações. 
Vários estudos têm revelado as dificuldades na efetivação da integração curricular no contexto dos IFs. Um dos obstáculos pode ser a ambiguidade dos pressupostos presentes nas normativas dos IFs e nas DCN-EPT, que apresentam discursos antagônicos na defesa do currículo integrado. Nesse contexto, seria interessante uma discussão ampliada sobre qual noção de currículo integrado tem norteado o trabalho nos IFs e uma análise de seus efeitos. Essa discussão poderia amparar o coletivo escolar na revisão dos PPCs e ao mesmo tempo alimentar a revisão das prescrições dos IFs a partir do currículo em ação que está sendo desenvolvida no "chão da escola".

Com exceção do Campus 2, os PPCs elaborados pelos campi quase sempre se restringem aos itens obrigatórios, abordando apenas superficialmente os aspectos relacionados às concepções pedagógicas do campus e deixando dúvidas acerca do processo de elaboração enquanto fruto de discussões coletivas. Em sua maioria, os PPCs são documentos burocráticos, que atendem às exigências da Reitoria e pouco orientam a respeito da formação integral que o campus se propõe a oferecer. Essa lacuna pode dificultar a integração pretendida para essa modalidade de ensino e favorecer o isolamento e fragmentação dos diferentes componentes curriculares integrantes de um mesmo curso, assim como o isolamento dos diferentes cursos de um mesmo campus.

Foi possível identificar nos PPCs alguns rastros no sentido da educação politécnica e omnilateral pretendida para o EMI dos IFs, ou seja, rastros do que foi formulado na dimensão macro, contudo a maioria desses documentos incorpora o discurso neoliberal ao atrelar a educação institucionalizada aos objetivos estreitos de preparação para o trabalho e na afirmação de uma identidade baseada no mercado (NEIRA; NUNES, 2009). Desse modo, a maioria dos PPCs apresenta características similares às prescrições do IFMG, por também revelar uma prevalência da racionalidade técnica e do discurso eficientista, seja ao enfatizarem questões relacionadas à organização, eficiência e avaliação, seja ao ignorarem os conceitos relacionados à emancipação, relações sociais de produção, identidade e diferença, característicos das teorias críticas e pós-críticas. Embora os PPCs dos campi reproduzam normativas dos IFs, como excertos das DCN-EPT e da Lei $n^{\circ} .11 .892 / 2008$, a maioria deles demonstra apropriações que se aproximam mais das concepções contidas nas prescrições do IFMG do que das concepções presentes nos documentos fundantes dos IFs.

\subsection{A jornada escolar em tempo integral}

Os cursos de EMI do IFMG são ofertados em jornadas de tempo integral. A jornada escolar dos estudantes dos campi da região metropolitana varia em relação aos horários de início e término das aulas, contudo em todos os campi os estudantes têm aulas no período da manhã e da tarde, durante os três anos do curso. Os cursos analisados têm cargas horárias que variam de 3.100 a 3.465 horas.

A carga horária descrita não inclui o intervalo destinado ao almoço e os dois intervalos de lanche; além disso, também há alguns horários vagos durante a semana. No Campus 1, por exemplo, os estudantes cumpriam uma jornada diária superior a 10 horas, pois suas aulas tinham início às 7 h20 e término às $17 \mathrm{~h} 40$, de segunda a sexta-feira.

Programas de ETI no Ensino Fundamental e no EM foram estimulados a partir da criação do PME e do ProEMI. Contudo, nota-se na educação brasileira descontinuidades nas políticas públicas relacionadas às mudanças de governo. As políticas para o EM são fortemente impactadas pela tendência de "hiperatividade no âmbito legal [...] sobrepondo o tempo político ao tempo necessário para efetivamente realizar mudanças na educação" (KRAWCZYK, 2014, p. 22). Os coletivos escolares nem sempre dispõem do tempo, de recursos e da autonomia necessários para se apropriarem das normativas e ressignificá-las de acordo com os desejos e necessidades daqueles que convivem na escola.

Muitos pesquisadores dedicaram-se ao acompanhamento e à avaliação das políticas educacionais implementadas nas últimas décadas. Apesar do aumento expressivo de publicações acadêmicas, que comunicam os resultados dessas pesquisas e apontam possibilidades de aprimoramento das políticas educacionais, temos convivido com a imposição de sucessivas reformas que desconsideram as contribuições do meio acadêmico e as vozes do coletivo escolar.

Em 2014 o ProEMI estava presente em 5.600 escolas, nas 27 unidades da Federação (LORENZONI, 2014). Uma pesquisa coordenada por Monica Ribeiro da Silva (2016a), que analisou a implantação do 
ProEMI, apontou que as induções feitas pelo ProEMI se mostravam enfraquecidas no que diz respeito ao pretendido redesenho ou reestruturação curricular; eles reforçaram a hipótese de que predominam atividades, projetos e oficinas desarticulados da base curricular estruturada em disciplinas, e que os macrocampos são percebidos mais como conjunto de atividades e práticas pedagógicas independentes e menos como eixos indutores de integração e reformulação curricular. Em muitos casos, ficou evidente o sentido de que as atividades derivadas do ProEMI se constituíam como ação extracurricular, e isso marca uma percepção do programa no sentido de seu isolamento ou no máximo de complementaridade em relação às demais ações da escola (SILVA, 2016a). Apesar dos distanciamentos entre os princípios do ProEMI e as apropriações feitas por professores e gestores, a autora conclui que houve benefícios para os estudantes.

Assim como o ProEMI, os programas de ETI para o Ensino Fundamental também apresentaram problemas durante a implantação. De acordo com Barreto e Sá (2016), o contexto da realização está distante do contexto da formulação no que se refere às finalidades da ETI presentes nos documentos oficiais. Ainda não há uma visão clara sobre o currículo da escola de tempo integral e essa política está sendo implementada de forma precipitada e com recursos insuficientes. Num ambiente de desconfianças, incertezas, improvisos e falta de condições adequadas, as escolas, pressionadas por interesses eleitorais, são obrigadas a implantar o tempo integral sem que haja diálogo e orientação. Nos contextos pesquisados pelas autoras, as experiências são heterogêneas e os avanços, quase sempre insuficientes para atender à meta prevista no PNE.

Os estudos sobre ETI (BARRETO; SÁ, 2016) apontam alguns problemas que não se evidenciaram no presente estudo, tais como: 1) precarização das condições de trabalho dos educadores, insuficiência e falta de qualificação dos recursos humanos, e 2) desinteresse dos jovens em participar dos projetos desenvolvidos para além do horário das aulas. Entretanto os dados da presente pesquisa revelam problemas específicos do IFMG, tais como: 1) o confinamento dos jovens nas salas de aula; 2) a sobrecarga imposta aos estudantes, e 3) a invisibilidades das demandas juvenis.

Algumas questões identificadas no IFMG são comuns àquelas verificadas nos programas de ETI de outras redes, tais como: 1) interesses políticos que impõem a acelerada implantação das políticas educacionais sem a infraestrutura adequada; 2) falta de integração curricular; 3) falta de envolvimento do coletivo docente na construção de um currículo que se pretende integrado, e 4) jornadas escolares excessivamente extensas que dificultam aos jovens o acesso a espaços e tempos para além do âmbito escolar.

Gariglio (2002) identificou algumas características institucionais típicas de uma escola profissionalizante quando realizou sua pesquisa no Cefet-MG. Uma delas refere-se à reduzida possibilidade de estudos independentes e individuais, devido à extensa jornada escolar que obriga os estudantes a permanecerem muito tempo face a face com seus colegas e com os servidores da instituição. Essa situação resulta numa limitação de aprendizagens sociais e culturais.

A Pesquisa de Silveira (2017) revelou a escassez de tempos e espaços que privilegiam as culturas juvenis e como os estudantes são forçados a renunciar ao tempo presente para investir num tempo futuro. Quanto tempo sobra para o jovem conviver com sua família, para as sociabilidades juvenis, para explorar e se apropriar dos espaços públicos da cidade e de sua programação cultural, para o engajamento político, para a privacidade, para o repouso? Isso é condizente com a pretendida formação integral ou é um processo de naturalização do estresse, que faz precocemente esses jovens se adaptarem às rotinas extenuantes, similares às rotinas da grande massa de trabalhadores da sociedade capitalista, que absorve o tempo e a energia da maioria da população em benefício do acúmulo de capital de poucos? Talvez essa seja a preparação para o trabalho desejada pelo setor produtivo. No sentido oposto, Krawczyk (2014, p. 31) alerta que os projetos pedagógicos do EMI deveriam contemplar as necessidades de tempo e espaço dos jovens.

Fala-se de extensão da jornada a partir de sete horas e já temos estados onde os alunos ficam 9,5 horas na escola. Duas horas a mais ou duas horas a menos não afeta a vida do estudante? O horário escolar é compatível com o relógio interno da adolescência? Que 
significa para um adolescente ficar numa instituição por tantas horas? Será que sua possibilidade de aprendizagem melhora? Que projeto pedagógico poderia otimizar esse tempo escolar? Existem projetos divergentes por trás das demandas por implementação da jornada completa? Estas e outras tantas perguntas estão ausentes no debate educativo. De forma aligeirada, pretende-se implementar uma política que muda a lógica do tempo e do espaço, que são os alicerces da organização escolar tal como a conhecemos.

Os IFs apresentam em suas normativas interessantes contribuições para a ETI, tais como: o currículo integrado; a formação omnilateral; os eixos trabalho, ciência, tecnologia e cultura; a tríade ensino-pesquisa-extensão; docentes com dedicação em tempo integral, entre outras. Os coletivos escolares podem se apropriar dessas contribuições, dos estudos publicados sobre os IFs e dos outros tantos em andamento na tentativa de ressignificá-los e ajustá-los à realidade local. Tal processo pode ser a base para discussão dos PPCs, para atingir níveis mais elevados de excelência educacional, produzir conhecimentos que subsidiem o aprimoramento das políticas públicas e corrigir as falhas dos programas de ETI. Esse pode ser um caminho bem mais interessante do que a hiperatividade no âmbito legal observada nos últimos anos.

Quando o coletivo escolar se liberta do controle do quadro de horário escolar, quando ele desfruta de tempos coletivos, potencializam-se as possibilidades de construir um currículo integrado. O Campus 2, que gozou de tempos e espaços privilegiados para a construção curricular, em relação aos outros três campi, conseguiu desenvolver PPCs que se aproximam da pretendida integração curricular. Além disso, é o que oferece o curso com a menor ${ }^{5}$ carga horária de aulas, entre todos os cursos do IFMG (IFMG, 2018). A ampliação dos tempos e espaços fora de sala de aula pode ser muito benéfica também para os estudantes do EMI, pois desse modo há maior flexibilidade para engajamento nos projetos de ensino, pesquisa e extensão desenvolvidos nos campi, além de favorecer a participação em atividades de monitoria, de estágio, do grêmio estudantil e de sociabilidades juvenis.

\section{CONSIDERAÇÕES FINAIS}

Se o texto curricular tem seu valor à medida que difunde os códigos sobre o que deve ser a cultura nas escolas, tornando-os públicos, é possível afirmar que os códigos presentes nos PPCs analisados são por vezes truncados, principalmente aqueles relacionados à formação integral, por invisibilizar as múltiplas dimensões da formação humana e as concepções pedagógicas que fundamentam os projetos. Por outro lado, os PPCs exortam os interesses do mercado e o produtivismo, conferindo a estes dois aspectos uma centralidade equivocada para se pensar a formação para o trabalho, naturalizando a ideia de que a escola deve se colocar à serviço do mercado de trabalho e revelando a perpetuação da influência das reformas educacionais do final do século XX, atravessadas pelo discurso neoliberal.

Outra problematização necessária diz respeito ao tempo da escola, que muitas vezes submete o currículo aos condicionantes do tempo do trabalho. A escola de tempo integral que ocupa o tempo das crianças e dos jovens, que os tira das ruas, que molda seus corpos para suportarem a exaustão e a contenção das extensas jornadas, que os prepara para a divisão social do trabalho e que aumenta a disponibilidade de pais e mães para o trabalho (mal)remunerado ao terem onde deixar seus filhos, está claramente direcionada aos interesses dos setores produtivos e pouco se importa com as crianças e os jovens que permanecem dos 4 aos 17 anos compulsoriamente ligados à escola.

Portanto, seria muito salutar pensar em novos ordenamentos e prioridades nos currículos das escolas de tempo integral, alinhados aos interesses mais amplos da sociedade, em especial aos interesses e necessidades das crianças e jovens. Outras escolas são possíveis, as prescrições curriculares não têm poder absoluto sobre o cotidiano escolar. Mesmo sob restrições de tempos e espaços, o currículo em ação pode ser insurgente e ressignificar o texto curricular a partir de um olhar mais humano, que

\footnotetext{
${ }^{5}$ Entre os campi estudados, o curso com menor carga-horária é o de Administração - Campus 2, com 3.100 horas (mínimo exigido para esse curso), e o de maior carga-horária é o de Mecânica - Campus 1, com 3.465 horas, que excede em 265 horas o mínimo previsto. Há cursos no IFMG com situação alarmante, como o curso de Meio Ambiente do campus Governador Valadares, que tem 4.360 horas, sendo que a carga-horária mínima para esse curso é de 3.200 horas (IFMG, 2018).
} 
Doi: 10.22478/ufpb.1983-1579.2020v13n1.50698

http://periodicos.ufpb.br/ojs2/index.php

considere principalmente os direitos dos educandos.

\section{REFERÊNCIAS}

ARROYO, M. G. Educandos e Educadores: seus Direitos e o Currículo. Indagações sobre currículo. Brasília: Ministério da Educação, Secretaria de Educação Básica, 2007.

BARRETO; E. S. S.; SÁ, K. R. Educação em tempo integral: contribuições oriundas das pesquisas de pósgraduação. Cadernos Cenpec, São Paulo, v.6, n.1, p.23-46, jan./jun. 2016.

BEZERRA, D. S. Ensino médio (des)integrado: história, fundamentos, políticas e planejamento curricular. Natal (RN): Editora IFRN, 2013.

BRASIL. CNE/CP. CONSELHO NACIONAL DE EDUCAÇÃO. Conselho Pleno. Parecer $n^{\circ} .11$ de 30 de junho de 2009. Apreciação da Proposta de Experiência Curricular Inovadora no Ensino Médio. Brasília: CNE/CP 2009C. 21p. Disponível em: <http:// portal.mec.gov.br/dmdocuments/parecer_minuta_cne.pdf>. Acesso em: 10 maio 2015.

BRASIL. CNE. Câmara da Educação Básica. Resolução n. 2 CNE/CEB, de 30/01/2012. Define Diretrizes Curriculares Nacionais para o Ensino Médio. Diário Oficial da União, Brasília, DF, 31 de janeiro de 2012. Seção 1, p. 20.

BRESCI, M. S. Origem e evolução do IFSULDEMINAS Campus Inconfidentes: qual o princípio pedagógico?152f. Tese (Doutorado em Educação). Faculdade de Educação, graduação, Universidade Nove de Julho (UNINOVE), São Paulo, 2017.

CAVALIERE, A. M. Escola pública de tempo integral no Brasil: Filantropia ou política de estado? Educ. Soc., Campinas, v. 35, nº.129, p. 1205-1222, out. -dez., 2014.

FLICK, Uwe. Introdução à pesquisa qualitativa. $3^{\text {a }}$. Ed. - Porto Alegre: Artmed, 2009.

GADOTTI, Moacir. Educação Integral no Brasil: inovações em processo. São Paulo: Editora e Livraria Instituto Paulo Freire, 2009.

GALIAN, Cláudia V. A.; SAMPAIO, Maria das Mercês F. Educação em tempo integral: implicações para o currículo da escola básica. Currículo sem Fronteiras, v. 12, n. 2, p. 403-422, maio/ago. 2012.

GARIGLIO, J. A. Educação Física no currículo de uma escola profissionalizante: um caso sui generis. Revista Brasileira de Ciências do Esporte, Campinas, v. 23. n. 2. p. 69-88, janeiro, 2002.

IFMG. Instituto Federal de Educação, Ciência e Tecnologia de Minas Gerais. Pró-reitora de Ensino. Orientações para elaboração e atualização de projetos pedagógicos dos cursos técnicos do IFMG, 2012. Disponível em: <https://www2.ifmg.edu.br/portal/ensino/OrientaesElaboraoAtualizaoPPCCursosTcnicos.pdf>. Acesso em 04 jan. 2018.

. Instituto Federal de Educação, Ciência e Tecnologia de Minas Gerais. Conselho Superior. Plano de Desenvolvimento Institucional 2014-2018. Documento integrante da Resolução IFMG 019 de 09 de julho de 2014.

médio do IFMG, 2018.

. Pró-reitora de Ensino. Análise e perfil curricular dos cursos da educação profissional técnica de nível

INEP. Instituto Nacional de Estudos e Pesquisas Educacionais Anísio Teixeira. Sinopses Estatísticas da Educação Básica, 2014 - 2019. Disponível em: <http://portal.inep.gov.br/web/guest/sinopses-estatisticasda-educacao-basica>. Acesso em: 15 fev. 2020.

KRAWCZYK, N. Ensino Médio: empresários dão as cartas na escola pública. Educação \& Sociedade, Campinas, v. 35, n. 126, p. 21-41, jan. Mar. 2014.

LOPES, A. Políticas de integração curricular. Rio de Janeiro: Eduerj, Faperj, 2008.

LOPES, A. C.; MACEDO, E. F. Disciplinas e integração curricular: história e políticas. Rio de Janeiro: DP\&A, 
2002.

LOPES, A. C.; MACEDO, E. F. Teorias de currículo. São Paulo: Cortez, 2011.

LORENZONI, I. Educação Básica. Ensino Médio Inovador receberá adesão de escolas em fevereiro. Portal MEC, Brasília, 21 jan. 2014.2 Disponível $<$ http://portal.mec.gov.br/index.php?option=com_content\&view=article\&id=20164:ensino-medioinovadorrecebera-adesao-de-escolas-emfevereiro\&catid=389\&itemid=86> Acesso em 27 dez. 2016.

MAURíCIO, L. V. Escritos, representações e pressupostos da escola pública de horário integral. Em Aberto, Brasília, v. 22, n. 80, p. 15-31, abr., 2009.

MOREIRA, A. F. B.; CANDAU, V.M. Indagações sobre currículo: currículo, conhecimento e cultura. Brasília: Ministério da Educação, Secretaria de Educação Básica, 2007.

MOURA, D. H. Políticas públicas para a educação profissional técnica de nível médio nos anos 1990 e 2000: Limites e possibilidades. In OLIVEIRA, R. (Org.). Jovens, Ensino médio e educação profissional: políticas públicas em debate. Campinas, SP: Papirus, 2012.

NEIRA, M. G.; NUNES, M.L. F. Educação Física, currículo e cultura. São Paulo: Phorte, 2009.

QVORTRUP, Jens. Visibilidades das crianças e da infância. Linhas Críticas, Brasília, v. 20, n. 41, p. 23-42, jan./abr. 2014.

QVORTRUP, Jens. A dialética entre a proteção e a participação. Currículo sem Fronteiras, v. 15, n. 1, p. 1130, jan./abr. 2015.

SACRISTÁN, J. G. O que significa o currículo? In SACRISTÁN, J. G. (Org). Saberes e incertezas sobre o currículo. Porto Alegre: Penso, 2013.

SILVA, M. R. O programa ensino médio inovador como política de indução a mudanças curriculares: da proposta enunciada a experiências relatadas. Educação em Revista. Belo Horizonte v.32, n.2, p. 91-110, abr.jun. 2016a.

SILVA, T. T. Documentos de identidade: uma introdução às teorias de currículo. 3. ed. Belo Horizonte: Autêntica Editora, 2016.

SILVA, M. A.; SILVA, L. O.; MOLINA NETO, V. Possibilidades da Educação Física no Ensino Médio técnico. Movimento, Porto Alegre, v. 22, n. 1, p. 325-336, jan./mar. de 2016.

SILVEIRA, A. G. Marcas do tempo integral nas juventudes: um estudo de caso em um Instituto Federal do Espírito Santo. Tese (Doutorado em Educação) - Faculdade de Educação, Universidade federal do Espírito Santo, Vitória-ES, 2017. 